\title{
Innovation driven design lead--Exploration of innovative development mode under the guidance of design thinking
}

\author{
HaiBo Yang
}

The central city of Shandong province Ji'nan city nanxinzhuang Road No. 336, University of Jinan Academy of Fine Arts, China

Email:57922807@qq.com

Keywords: Innovate;Design thinking;Industrial design;Transformation and upgrading.

\begin{abstract}
Scientific thinking drives social progress with historical value, but th-ere are limitations. It is inevitable for design thinking to lead the development of human society. Design thinking combines technological, commercial, and cu-ltural elements with innovative approaches to problem solving. By reviewing the development process of industrial design, analyzes the inevitability of the characteristics and design thinking of the innovation development, clarify the path to realize the design of the wisdom to lead the system innovation, and th-rough the case that industrial design is to strengthen innovation driven, boost industrial development path and the focal point, leveraging active introduction, to promote manufacturing China create ascending China.
\end{abstract}

\section{The inevitability of innovation driven and design led}

\section{1 scientific thinking drives the historical value and limitations of social progress}

In 1637, Descartes published the book "the correct thinking and method of scientific truth theory"; in 1644, another of his works "philosophy principle", "I" become the absolute subject, but as a natural object in front of me there. Ba-sed on this theory, the West has established a social system, with efficiency first and the pursuit of higher, faster and stronger science and technology beco-ming the only standard source of human thinking and value judgment.

Google has published such a string of data: human walking from upright to four million years in 2003, created a total of 5 bytes of information, equivale-nt to 5 billion 1G movies. 2017 - 5 bytes are created every 1 minutes. It can be said that with the rapid advance of science and technology and the rapid development of the transformation of natural ability, human self-confidence and material desires have never been inflated. However, immersed in the "heaven human race" under the guidance of the thought of accelerating repeatedly did not make us happier and more relaxed or more creative, not to mention the many contradictions of extinctions, environmental pollution, disease rising and problems. Society is full of impetuous pursuit of material comforts and privat-e possession, lack of spiritual belief, neglect of inward introspection and reflect-ion.

The development of modern theory and model to the guiding ideology, is human centered, to meet people's needs and solve problems as the starting poi-nt, often ignore (active or passive neglect) consumption of resources production, use and scrap processing as well as the impact on the environment. Under

the guidance of this logic of thinking, to the second half of the twentieth Cent-ury, human consumption of natural resources exceeded the speed of renewable natural resources. Today, the reality proves that the western world has domina-ted the "black" modern development model characterized by human centered,

consumerism driven, and characterized by the "three high". Science and techn-ology is an important means for human beings to build a better life, not an

end. At the moment, finding the balance between survival and development 
becomes the greatest test of wisdom. Industrial civilization and scientific and te-chnological thinking are facing amendment. The world needs to rebuild its val-ues; it needs to establish a pre industrial era evaluation standard that is differ-ent from the western ones.

\section{2 design thinking leads the age inevitability of human society development}

The design runs through the whole process of human civilization development. The wisdom of design contains the goodness of religion, the beauty of art and the truth of Science (shown in Figure 1). Its essence is the comprehensive pl-anning of all aspects of things, and create a more harmonious way of survival and development. Chinese traditional innovation (creation, design) stems from the idea of "heaven" in plain view, especially Taoism on the universe of "Tao", grasp the depth of human nature of "Confucian" positive praise, in the "moral" in human nature and the human body directly and "natural" related. "Laws, law day, days France Road, imitation of nature". The human is part of the uni-verse, man and nature are closely linked with the development of. The harmo-ny between man and nature, harmonious existence view, development view that we have reason to believe, to create the future of mankind is not only inventing new technologies and new tools to pursue "faster higher stronger" under

the guidance of scientific thinking; how to make use of science and technology, human vision and ability dimension change, to put forward the concept of

development new theories and solutions is imperative. So, in the continued hu-man evolution process, design thinking can cultivate our inner potential,we canarouse the pursuit of pure, harmonious and beautiful ideal, can measure the sta-ndard and mode change has been created, has not experienced and better surv-ival and development. We have reason to believe, based on over 5000 years of civilization heritage on the basis of China have the ability to establish a dif-ference from the Western dominated evaluation standard, to have confidence in the way the theory of confidence, institutional self-confidence, cultural self-confidence.

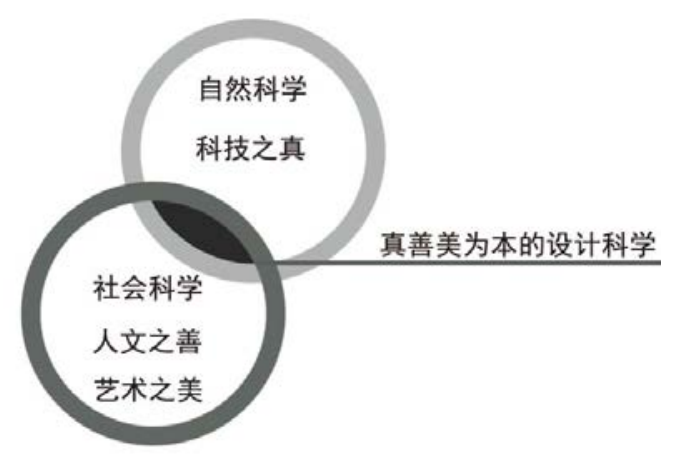

Figure 1

\section{Design intelligence leads to the realization path of system innovation}

\subsection{Characteristics of design thinking}

Design is not knowledge upgrading,but cognition evolution. The design createsa better way of life and shape by rearranging the elements and integrating reso-urces.Design objects include Vientiane,products,industries,services and enterprisecan be re creative,re design.Innovative design is a multidisciplinary and compre-hensive process, including user research, marketing, product design, industrial design,digital design,design management and brand building. The creative design of the integration of resources and personalized user needs to weigh all the possibility,feasibility and realistic factors,combined with the comprehensive facto-rs of cost, profit maximization and market effect, and ultimately determine thedesign direction and ideas, the formation of innovation works or products.

The innovative design of the new design concept,to obtain the user benefit maximization as the goal, with the latest research results as the basis,combinedwith the designer's own experience and 
inspiration,the new product function str-ucture,through the design thinking,new design means,create new style, features, newfeatures,ultimately achieve harmony and unity the function and aesthetic.Thecritical path to achieve scientific and technological innovation is the innovative design, designers through the application of the theory and research results, combined with the object of optimization and integration of intellectual labor and wisdom to create, and ultimately result application.

The rise of Industrial Design is the contemporary embodiment of design intelligence.Industrial design is the product of industrial development and divisi-onof labor.It is multidisciplinary activity designed to solve the strategic proble-ms of products, services and enterprises in combination with theory, echnology andaesthetics.At present, our government, business circles and academic circles are confused about the connotation and denotation of industrial design. The design is often misinterpreted in modern china. The designer is an artist,design is caring rather than self expression; the designer is the executor of design is defined instead of focusing attention and shaping; the designer is the leader, the whole process of collaboration design is rather than heroism; designer is the inventor, design is the creation of demand rather than inventing new tech-nologies; design is a new product design strategy is to upgrade not only is the product replacement;design means high cost, the design is to create high valu-eadded and high prices. How to apply design thinking to realize the structural reform of supply side and realize the innovation of product and service design is the key to designers.In the supply side reform assessment,as a cross-border integration designers need to have the following capabilities:grasping the needs, knowledge, technology, culture, creativity, production, standards, systems, mark-eting. Designers bear the responsibility of knowledge, theory and strategy planning,and the cultivation of cross boundary design thinking needs to further im-prove the educational system, reform the teaching methods and design the high degree of unity of cognition.

In recent years, China industrial design is experiencing unprecedented rapid development.Data show that the industrial design center nearly 5000, major in industrial design companies in more than 6000 domestic design, creative park nearly 3000, more than 1000 universities majoring in industrial design, the industrial design directly engaged in the total number of nearly 300 thousand people. Each year, there are nearly 600 thousand graduates majoring in design,about more than 60 industrial design organizations,64statelevel industrial designcenters, and more than 1800 provincial and municipal industrial design centers in 22 provinces and municipalities. Shandong provincial industrial design center189, industrial design Park 16 (data by the end of 2016).

\section{2 design wisdom leads to three aspects of social innovation}

To realize economic growth and social innovation,we should't only enlarge the demand and stimulate consumption, but also change a new way of thinkingand new methods for supply side reform, so as to solve the existing economic problems".From the supply side to the demand side, what has been purchased from the previous outputs, what is needed now, and what is produced,Design service production $\rightarrow$ Design meets demand $\rightarrow$ Design guidance requirements $\rightarrow$ Desi-gn creates demand Process change. The construction of Characteristic Towns and beautiful villages has pointed out the direction for the transformation and upgrading of agriculture.The innovation of the mode of health care reform andhome care system construction witnessed the transformation of public service function of the government. All top-level design reforms need the guidance of design thinking, whether it is the first industry, the second industry and the reform of the third industry,are interlinked. It is a historical necessity to lead the innovation drive and realize the supply side reform, which conforms to the objective law.

The design logic thinks that all the human life styles are made up of things and things. The "thing" is the starting point of the design activities, together with the spiritual aspects of ideas,values, which constitutes the whole meaning of the design innovation.The first is the object: the utensil layer, the tool of production and life. Chinese use chopsticks, Westerners use knives and forks; second is that the organization , the system consists of many factors linked to each other in certain ways, including production technology and political orga-nization,business model,festival 
activities,dining etiquette; the third is: the value level, based on the above thinking and make some sense the cognition, understanding, judgment or choice, that is , things that set the debate is a kind of thinking or non orientation. The three levels are inseparable,forming an organic whole---System.

At present,the development of industry and information technology integration,new technology and new thinking of the Internet, big data, 3D printing, virtualreality bring profound influence and disruptive to the whole industry ecosystem, industrial structure, production relations. Under the modern industrial system, the industrial design highlights its supporting role, and its service mode also turns to the high-end integrated design service. Industrial design is no longer limited to the special design of goods, and is no longer attached to "business and technology".The design of sharing service with innovation as the core prov-ides the path of sustainable development of human beings. Industrial design has become the unity of modern science and technology and art, economy and culture, innovation and development, and become the key to the coordinated development of industries. The core of regional cooperative development has become the methodology of social innovation in the industrial era.

\section{3 industrial design leads the three aspects of enterprise innovation}

From Chinese society is taking economic construction as the center to the center for change in the social construction,this change is not only to the con-struction of is more strong,rich in manufacturing and technology of the countryforward, is process of transformation from the traditional society to the modern cultural value of knowledge economy and Science and technology civilization. The traditional social class has produced a new change: has become the foundation of experience, innovation driven design has become, technology and kno-wledge has become the source of wealth. The China society will change from the consumption culture to the industry bring huge dynamic. From the demand side to the supply side reforms, from factor driven to innovation driven, the lack of the original design is not only the integration of high-tech "object", the government is to design innovation as the starting point of the coordinateddevelopment of six industries. To promote the design of enterprise innovation, we must make six cognitive changes: from the end to the starting point, from product to service, from creativity to entrepreneurship, from coping to manage-ment, from instinct to intelligence, from exogenous to endogenous.

Three levels of innovation in industrial design service enterprises:1., product processing---Sales led enterprise.Anti risk ability is small,autonomy is poor,the main consideration is to reduce costs, pay attention to marketing, do not pay attention to industrial design.2.technology led---Design outsourcing enterprise. To improve product design, focusing on the form level.3.brand marketing---Selfhelp innovative design enterprise.From paying attention to the product paying attention to the brand,more and more attention has been paid to the promotion of the overall image level of the enterprise, and the enterprise needs to understand the potential demand of the users so as to better meet the needs of the market development. Not only concerned about the current product, but more concerned about the future development of enterprises, technology and demand in the two wheeled drive innovation.

\section{Case study on innovation development of industrial design}

In the face of strategic planning,the current domestic and international econ-omic situation and the construction of innovative country in recent years,Shandong province will strengthen as the development of industrial design innovation driven,boost industrial development an important focal point, leveraging active introduction, build advanced industrial design service platform of traditional industries, to promote the "China manufacturing" to "China made" upgrade.

(a) the power of traditional product design manufacturing quickly mention desi-gn case

1. industrial design and research with Suit chair as an example

Design comfortable chair, not only need to consider the size of the anasto-mosis, process precision,pay more attention to the interaction between man and the chair, and chair in the whole 
office environment, art and culture exchange.Chair design is a clever solution to various performance needs and price costs.

The design team collecting the product data (including historical data), sum-marized from the typical and representative products and brands,for these produ-cts and brands in the history of contemporary plays the role of research.Study on its product development process, the functional and morphological changes, the background of the times, the product technology, technical characteristics and conditions for social groups, research and analysis to establish a macro ass-essment of the product standard.

Mature and complete core technology research and development is a long and arduous process. The product has China cultural features in addition to the core technical requirements to meet the basic functions of excellent products, but also have high grade appearance styles to integrate into the modern office environment, and make prospects for future inspiration. Suit is the first bold attempt of this concept. Its style is based on the lifestyle of modern office envir-onment and has the characteristics of Chinese culture.

2. The product design for Shandong Yinying cooking machinery

Shandong Yinying cooking Machinery Co. Ltd is a high-tech enterprise in domestic kitchen equipment design and development, manufacturing, logistics, sales and service as one of the terminal.In order to adapt to the new economic norm, the development trend of Internet plus industry and customer demand, enterprises need to upgrade the design of replacement products.The design teamto explore eagle is simple and elegant,sharp lines design elements,the exposed will not see messy function module planning to a series of removable combination;packaging the whole line and components, realize safe operation, sanitation, humanization, enhance the product quality. Through carding, mining products and enterprise core strengths, establish brand image,and help enterprises consolidate the leading position of the industry. A strategic partnership, profit sharing; a total of China cooking group design and Research Institute of mechanical industry, enterprise R \& $\mathrm{D}$ designers accept industrial design training, product design won the Shandong provincial governor Cup "Industrial Design Competition Award, greatly enhance the added value of products.

(b)tap cultural traditions and comparative advantages to help brand building and upgrading

1., a series of research and development of tourist commodities based on Shandong cultural characteristics

Lotus: lotus flower humidifier in Ji'nan as the prototype for the creative design, elegant temperament fit the lotus humidifier product quality. In green products as a base, lotus flower shaped lining, vivid image. When in use, water vapor, aesthetic mood, "autumn lotus dew, falling above tien.The future of jade plate, is beginning to know the circle." The humidifier program won the "Twelfth Shandong tourism commodity innovation design competition" outstanding award.

Black rattan: Design of the humidifier humidifier with water droplets shape, taking Ji'nan Zhangqiu black as traditional straw process with contrast material, distinctive. Product exudes a strong Chinese classical cultural charm, showing exquisite taste of life.

Taiyu gentleman table: This design selected Taishan jade as substrate surface inlaid with precious metals such as gold and silver; pattern design for Tai'an scenic, cultural and historical allusions, "Taishan sunrise, Taishan pine, Taishan stone, Feicheng peach blossom" is a picture, can according to different gender, age, occupation of the consumer requirements design series product. Taishan jade table, meaning steady, precious, accurate punctuality.

2.Mei Xiang Pingyin, Shandong one world cultural tourism brand image system

"One world", this idea by exploring Pingyin natural landscape, cultural landscape, agricultural tourism resources, Pingyin rose, Taishan mountains,Dongpin

lake,Yuanchi Hong Quan,Hu Zhuang riyuequan, church, dove of peace, blessing card Ejiao will most local characteristics to simplify financial visionm in one.

"Mei Xiang Pingyin" is a phrase with a double meaning, with distinctive localcharacteristics, in line with the Pingyin city rural tourism development strategy positioning in response to the country, and people seem to linger in the rose fragrance, feel the tourist city that simple is full of youthful 
vitality.

3., combined with the local industrial base, to create innovative development model Shandong, Zibo,Boshan source Kiwi characteristic tourism industry town

Tourism image positioning: the love of landscape, peach source drunk.

According to the distribution characteristics and source of town tourism resources unique resources, resource type, the source of town tourism resources into green tourism resources, rural tourism resources, tourism resources, red tourism resources of religion and industrial tourism resources, historical and cultu-ral tourism resources of the six major resources sector.

(c) design and research to help enterprises to subvert innovation and lead the development of the industry

In view of China's future trends in science and technology, lifestyle, combinedwith Haier corporate culture as a global leader in white goods, create a new experience, a new market concept development. As consumers need is neither "ice" nor "box", but is able to provide safe and fresh food service system at any time. According to the market, user, technology and trend research and sta-tistics, four application interfaces are designed:the ingredient selection interface,the shopping cart interface,the order management interface and the health mana-gement interface. The user through the mobile phone into the Haier APP storeselection of goods, orders for payment,the merchant receives order picking, and put the goods into the storage module, door-to-door delivery, the user receives a storage module and commodities, the completion of the transaction, the mer-chant time door-to-door recovery storage module for cleaning and disinfection.

mobile air purifying range hood

Traditional cooking fume exhauster mainly divides, collects and discharges soot produced in the cooking process,resulting in two pollution of outdoor air.Sometimes, when we eat domestic hot pot and homemade barbecue, the cooking process of food is outside the kitchen, and it also causes a great deal of soot and hot steam in the course of eating. "Clean air" is designed for the above situation, a new type of mobile smoke exhauster with air purification function.Products using "turbo" technology will be the hot steam fume suction chamber after purification of the core technology,the pure air, so as to completely elim-inate the traditional oil smoke lampblack machine only air pollution shortcom,, is a subversive creative works, has a broad market space. The program won the award of excellence in 2014 the "lion Cup" international home appliance and consumer electronic product innovation design contest.

Any product has a design process, but not all innovations are led by design. Compared with the traditional R \& D drive innovation model, design leading innovation drive is not a new research technology, but a comprehensive application of cultural creativity and existing technology. In addition,design innovationdrives more emphasis on the relationship between products and people and soci-ety, and creates infinite possibilities of mankind through product innovation. With the rapid development of modernization and industrialization, the design culture of many developed countries has its own characteristics, and the United States adopts the policy of encouragement to form a design culture driven by innovation. Germany adheres to the scientific spirit of excellence,and relies on advanced engineering technology, industrial standards and vocational education in the global competition to form good faith and high quality design culture. The creation of China guided by innovative design should take the guidance of innovation and development, grasp the characteristics of the times, and guide China's design into the world and the world. Respect the design rules,seize the elements of innovation, emancipate the mind, seek truth from facts and accelerate the realization of "made in China" and "made in China".

\section{References}

[1] American scholar. China is in danger of losing its inherent Chinese traditio culture, August 25, 2017.

[2] Liu Guan Zhong. The design objective: to enhance the quality of life of $\quad$ J J . design.2015 (1). 
[3] Liu Guan Zhong.Chinese industrial design industrial structure mechanism of [J].design.2013 (10).

[4] David Wallace, Wells. Inhospitable earth, [J]., New York magazine, July 9, 2017

[5] Lao Zi.Moral science, [M]., Shandong science and Technology Press, 2008. 